\title{
Identification of warm day and cool night conditions induced flowering-related genes in a Phalaenopsis orchid hybrid by suppression subtractive hybridization
}

D.M. Li, F.B. Lŭ, G.F. Zhu, Y.B. Sun, Y.C. Xu, M.D. Jiang, J.W. Liu and Z. Wang

Guangdong Key Laboratory of Ornamental Plant Germplasm Innovation and Utilization, Environmental Horticulture Research Institute,

Guangdong Academy of Agricultural Sciences, Guangzhou, China

Corresponding authors: D.M. Li / F.B. Lü

E-mail: biology.li2008@163.com

Genet. Mol. Res. 13 (3): 7037-7051 (2014)

Received May 22, 2013

Accepted September 4, 2013

Published February 14, 2014

DOI http://dx.doi.org/10.4238/2014.February.14.7

\begin{abstract}
The influence of warm day and cool night conditions on induction of spikes in Phalaenopsis orchids has been studied with respect to photosynthetic efficiency, metabolic cycles and physiology. However, molecular events involved in spike emergence induced by warm day and cool night conditions are not clearly understood. We examined gene expression induced by warm day and cool night conditions in the Phalaenopsis hybrid Fortune Saltzman through suppression subtractive hybridization, which allowed identification of flowering-related genes in warm day and cool night conditions in spikes and leaves at vegetative phase grown under warm daily temperatures. In total, 450 presumably regulated expressed sequence tags (ESTs) were identified and classified into functional categories, including metabolism, development, transcription factor, signal transduction, transportation, cell defense, and stress. Furthermore, database comparisons revealed a notable number of Phalaenopsis hybrid Fortune Saltzman ESTs that matched genes with
\end{abstract}


unknown function. The expression profiles of 24 genes (from different functional categories) have been confirmed by quantitative real-time PCR in induced spikes and juvenile apical leaves. The results of the real-time PCR showed that, compared to the vegetative apical leaves, the transcripts of genes encoding flowering locus T, AP1, AP2, KNOX1, knotted1-like homeobox protein, R2R3-like MYB, adenosine kinase 2, S-adenosylmethionine synthetase, dihydroflavonol 4-reductase, and naringenin 3-dioxygenase accumulated significantly higher levels, and genes encoding FCA, retrotransposon protein Ty3 and C3HC4-type RING finger protein accumulated remarkably lower levels in spikes of early developmental stages. These results suggested that the genes of two expression changing trends may play positive and negative roles in the early floral transition of Phalaenopsis orchids. In conclusion, spikes induced by warm day and cool night conditions were complex in Phalaenopsis orchids; nevertheless, several molecular flowering pathway-related genes were found. The acquired data form the basis for a molecular understanding of spike induction by warm day and cool night conditions in Phalaenopsis orchids.

Key words: Phalaenopsis; Flowering gene; Spike induction; Gene expression; Flowering locus T

\section{INTRODUCTION}

Transition from vegetative to reproductive growth is one of the most important developmental changes in the angiosperm life cycle. The transition is controlled by both internal signals and external environmental factors, which later integrate to result in flowering. In the dicot model Arabidopsis, for example, five genetically defined pathways - photoperiod, vernalization, gibberellin, autonomous, and aging - have been identified in the control of flowering (Srikanth and Schmid, 2011). The photoperiod pathway refers to regulation of flowering in response to day length and quality of light perceived, whereas the vernalization pathway monitors flowering on exposure to a long period of low temperature. The gibberellin pathway promotes flowering requirement of gibberellic acid for normal flowering patterns. The autonomous pathway refers to endogenous regulators that are independent of the photoperiod and gibberellin pathways, and the aging pathway, where plant age controls flowering time (Srikanth and Schmid, 2011). The flowering signals from these multiple genetic pathways ultimately converge on the regulation of two major floral pathway integrators, FT (flowering locus T) and SOC1 (SUPPRESSOR OF OVEREXPRESSION OF CONSTANS1), which in turn activate floral meristem identity genes, such as AP1 (APETALA1) and LFY (LEAFY), to initiate the generation of floral meristems (Abe et al., 2005; Corbesier et al., 2007; Lee et al., 2008; Lee and Lee, 2010).

Phalaenopsis, or moth orchid, belongs to Orchidaceae, one of the largest angiosperm families. It is a very popular and the most valuable potted plant in the world because of its stylish, elegant appearance and extended flowering period. Species of this genus are epiphytic crassulacean acid metabolism (CAM) plants (Endo and Ikusima, 1989; Guo and Lee, 2006), originating from tropical and subtropical areas of the South Pacific Islands and Asia. Their juvenile phase lasts up to 36 months from seeding for many commercial Phalaenopsis hybrids (Hew and Yong, 
1997), which makes it difficult to meet specific market dates. Several studies on the regulation of flowering in Phalaenopsis orchids are mainly concern the effects of temperature and photoperiod (Chen et al., 1994, 2008; Sakanishi et al., 1980; Wang, 1995). Moreover, compared with photoperiod, temperature is a more important environmental factor for inducing spikes in Phalaenopsis orchids. For commercial production, Phalaenopsis hybrids are always treated with low temperatures in temperature-controlled greenhouses or cultivated in naturally cool environments such as in high mountains to accelerate floral transition. During greenhouse production, the recommended average daily temperatures of $25^{\circ}-30^{\circ} \mathrm{C}$ are maintained to promote leaf development and inhibit flower initiation (Chen et al., 1994; Sakanishi et al., 1980). Conversely, fluctuating warm day $\left(28^{\circ} \mathrm{C}\right)$ and cool night $\left(20^{\circ} \mathrm{C}\right)$ conditions significantly induces the formation of spikes of Phalaenopsis plants (Chen et al., 2008). Furthermore, the effects of warm day and cool night conditions on Phalaenopsis plants have been studied with respect to photosynthetic efficiency, metabolic pools and physiology. For example, on the basis of the characteristics of CAM plants, warm day and cool night conditions affect photosynthetic efficiency, metabolizable carbohydrate and organic acid pools of Phalaenopsis orchids (Chen et al., 2008; Pollet et al., 2011a,b).

Although a number of expressed sequence tags (ESTs), transcriptomic and smRNA sequences obtained from Phalaenopsis reproductive organs have been deposited in GenBank or OrchidBase (Chen et al., 2005; Tsai et al., 2006; An et al., 2011; Hsiao et al., 2006, 2011), only a few of these genes and smRNAs have been characterized. Examples are ORAP11, ORAP13, CONSTANS-like, and FVE from Phalaenopsis orchids (Doritaenopsis included), which are believed to play important roles in floral transition and regulation of flowering time (Chen et al., 2007; Zhang et al., 2011; Sun et al., 2012). However, the molecular mechanisms of warm day and cool night conditions for flowering initiation in Phalaenopsis orchids, especially identification of central genes regulating flowering time as well as those controlling other processes affecting flowering, have not been well understood so far.

In the present study, we principally focused our attention on the identification of flowering-related genes in spikes of Phalaenopsis orchids induced by warm day and cool night conditions. One suppressive subtractive hybridization ( $\mathrm{SSH}$ ) cDNA library was constructed to compare genes differentially expressed between spikes induced by warm day and cool night conditions and juvenile apical leaves grown under warm daily temperatures. We searched Phalaenopsis homologs with known flowering genes by EST and bioinformatic analysis. A group of putative flowering genes corresponding to known genetic pathways regulating flowering time were identified. Among these genes, several genes were chosen for expression analysis of their spatial and temporal patterns between induced spikes and juvenile apical leaves. Information gathered on these genes is discussed and suggests that they can play important roles in floral transition induced by fluctuating warm days and cool nights.

\section{MATERIAL AND METHODS}

\section{Plant material and growth conditions}

In August 2010, mature, non-flowering plants with at least 5 fully developed leaves of Phalaenopsis hybrid Fortune Saltzman were purchased from a commercial farm (Flower Star, Foshan, Guangzhou, China), and grown in 2.5-inch diameter plastic pots filled with sphagnum moss in a greenhouse at the Environmental Horticulture Research Institute, Guangdong Academy 
of Agricultural Sciences, under natural light and controlled temperature. Prior to the experiment, plants were placed in a greenhouse for at least 2 weeks with day (70-95\% relative humidity, $\mathrm{RH}) /$ night $(100 \% \mathrm{RH})$ temperature regime of $28^{\circ} \pm 2^{\circ} \mathrm{C}$. Plants comprising the untreated group were subsequently grown at day $\left(28^{\circ} \pm 2^{\circ} \mathrm{C}\right) /$ night $\left(26^{\circ} \pm 1.5^{\circ} \mathrm{C}\right)$ (day $70-95 \% \mathrm{RH} /$ night $\left.100 \% \mathrm{RH}\right)$ to inhibit phase transition. Warm day and cool night treatment was carried out at day $\left(28^{\circ} \pm 2^{\circ} \mathrm{C}\right) /$ $\operatorname{night}\left(21^{\circ} \pm 1.5^{\circ} \mathrm{C}\right)($ day $70-95 \% \mathrm{RH} /$ night $100 \% \mathrm{RH})$ for 1.5 months to complete phase transition.

\section{Position and timing of sampling}

The apical leaves without cool night treatment were collected at 2-week intervals from 0 to 1.5 months. Reproductive stems, viz. spikes, were only present in the warm day and cool night treatment group. For Phalaenopsis hybrid Fortune Saltzman, spikes were collected at 0-3, $3-5,5-10,10-15,15-20,20-35$, and $40 \mathrm{~mm}$ in length, separately. Each sample was pooled from 3 separate plants and stored separately for all the experiments in this study.

\section{RNA extraction}

Total RNA was extracted using the RNeasy Plant Mini kit (Qiagen, Germany) according to manufacturer protocols. Total RNA was then treated by RNase-free DNase I (TaKaRa, Japan) to remove DNA contamination. The total RNA yield and quality were determined spectrophotometrically at wavelengths of 230, 260 and $280 \mathrm{~nm}$. The integrity of total RNA was checked by running samples on $1.2 \%$ denaturing agarose gels.

\section{Amplification by SMART technology and construction of subtracted complementary DNA (cDNA) library}

For SSH library, total RNA was extracted from spikes at $40 \mathrm{~mm}$ in length from the warm day- and cool night-treated group and vegetative apical leaves pooled at different untreated times of Phalaenopsis hybrid Fortune Saltzman. Total RNA (1.0 $\mu \mathrm{g}$ per sample) was reverse-transcribed and amplified to produce SMART cDNA using the SMART ${ }^{\mathrm{TM}}$ PCR cDNA Synthesis kit (Clontech, USA) according to the user manual.

The subtractive cDNA library was obtained using the PCR-select cDNA subtraction kit (Clontech). The tester (warm day- and cool night-induced spikes) SMART-cDNA sample was subtracted twice by the driver (untreated apical leaves) SMART-cDNA sample following manufacturer recommendations (forward subtraction). Subtracted cDNA sequences were then immediately ligated into the pGEM-T easy vector (Promega, USA), and transformed into competent cells of Escherichia coli DH5 $\alpha$ (TIANGEN, China). Transformed cells were seeded onto LB agar plates containing $100 \mu \mathrm{g} / \mathrm{mL}$ ampicillin, $1 \mathrm{mM}$ IPTG (isopropyl- $\beta$-D-thiogalactopyranoside), and $80 \mu \mathrm{g} / \mathrm{mL} \mathrm{X}$-gal (5-bromo-4-chloro-3-indolyl $\beta$-D-galactopyranoside), then incubated at $37^{\circ} \mathrm{C}$ overnight for blue-white colony screening. Individual recombinant white colonies were picked and grown in LB liquid medium containing $50 \mu \mathrm{g} / \mathrm{mL}$ ampicillin.

\section{cDNA sequencing and sequence data analysis}

Plasmids containing cDNA fragments were prepared on the Applied Biosystems 
3730 DNA analyzer (Shanghai, Invitrogen, China). The sequences were trimmed to eliminate vector and adaptor sequences prior to further analysis. Homology searches of all sequences were queried in the GenBank database by using the BLASTn and BLASTx search at the NCBI network service (http://www.ncbi.nlm.nih.gov/BLAST) (Altschul et al., 1997). The ESTs with significant matches using cut-off value 1e-5 were classified into functional categories according to the Gene Ontology database (http://www.geneontology.org). Sequence data of Phalaenopsis hybrid Fortune Saltzman have been submitted to the GenBank under the accession numbers indicated below.

\section{Analysis of differential ESTs by real-time PCR}

Differential EST expression levels in the spatial and temporal distribution of the juvenile apical leaves and spikes $(0-3,3-5,5-10,10-15,15-20$, and 20-35 mm) were detected by real-time PCR. cDNA of each sample was synthesized using the PrimeScript ${ }^{\mathrm{TM}}$ First-Strand cDNA Synthesis kit (TaKaRa) according to the manufacturer protocol. Primers for differential ESTs were designed with Prime Primer 5 (Table 1). Real-time PCR was carried out with SYBR Green I kit (TaKaRa) in a final volume of $20 \mu \mathrm{L}$, including $0.5 \mu \mathrm{L}$ forward primer $(10 \mu \mathrm{M})$, $0.5 \mu \mathrm{L}$ reverse primer $(10 \mu \mathrm{M}), 10 \mu \mathrm{L}$ SYBR Green Premix $(2 \mathrm{X}), 2.0 \mu \mathrm{L}$ diluted first-strand cDNA and $7.0 \mu \mathrm{L}$ sterile distilled water. The reactions were preformed in the Light Cycler 480 real-time PCR system (Roche Diagnostics, USA) using the following program: preheating at $95^{\circ} \mathrm{C}$ for $30 \mathrm{~s}$ followed by 40 cycles of $5 \mathrm{~s}$ at $95^{\circ} \mathrm{C}, 15 \mathrm{~s}$ at $58^{\circ} \mathrm{C}$ and $30 \mathrm{~s}$ at $72^{\circ} \mathrm{C}$. The levels of gene expression were analyzed with the Light Cycler 480 Software (Roche Diagnostics) and normalized with the results for actin (AY134752). Real-time PCR was performed in three replicates for each sample, and data are reported as means $\pm \mathrm{SD}(\mathrm{N}=3)$.

Table 1. Primer sequences used for quantitative real-time PCR.

\begin{tabular}{|c|c|c|c|}
\hline Clone No. & Forward primer $\left(5^{\prime} \rightarrow 3^{\prime}\right)$ & Reverse primer $\left(5^{\prime} \rightarrow 3^{\prime}\right)$ & Product length $(\mathrm{bp})$ \\
\hline FS33 & TGTGAAGGAGCGGCTTGATT & CTTCCTTCGCCTTCTTGATA & 215 \\
\hline FS71 & TGCTGAGTATGAGGGCTTGA & TCGCTTCGGACTTTCCAACT & 129 \\
\hline FS82 & TTTGCTTGACATTCCACCAG & TTTCСАТАСССТССТТТСТТ & 176 \\
\hline FS89 & CTATGCCCTCAGTTCTACCG & AGGTGGCAGTCCATCAGTCG & 248 \\
\hline FS184 & CTTCATTTAGGCGGTTCCAG & AGTGGAAGAACCTGGCTCAA & 138 \\
\hline FS210 & CCCACCCTATTGACCGAGTT & GTGCCCGAACTCATCCAAGC & 147 \\
\hline FS276 & GCAATCCTCCGCTCGCCTAC & CTCTTATGCCCGACCTCTTG & 153 \\
\hline FS278 & CAATCCAAAGACCCTGAGA & CTCAGGATGCCAAGCAAACC & 65 \\
\hline FS327 & TCAAGTCGGCGGTCTCCAAG & AATCGACCGTTGCTCAGGTA & 123 \\
\hline FS344 & AACGAGGGACACCCAGACAA & GAAACCGATGGAACGACAGG & 201 \\
\hline FS383 & GACAACATCTGCGGTCTGGC & TTTGAACCTCCACAGCACTT & 147 \\
\hline FS397 & GATGTGCCATTGGTCAGAAG & AACACTTCGCCAAACCTAAA & 193 \\
\hline FS449 & TCCTCAGTCATTTGGGTTCT & AGCAAATAATCGCTCACAGG & 286 \\
\hline FS469 & CAATCTGTCTAATCGCTCAC & GTAATGCCACGCCCTCCCAC & 101 \\
\hline FS494 & CTATTGGGCACCTTTCCTTG & CACAGAGCCTTTCATCCTAC & 180 \\
\hline FS527 & ACCGCTTTGTCTTCGTGCTG & CGACTGGCGAACCGAGATTA & 120 \\
\hline FS652 & ACAAGTTTATCTGGGAGGTT & ATTCTCCAGAGGGAAGTTGA & 112 \\
\hline FS715 & TTTCATAGGTCCGCAAGCAG & GTTGGTGCTGGTTCGGTTGG & 111 \\
\hline FS789 & CAGGGAGAACTGACAACGAA & GGATGGCAGTGCTTGATTTG & 113 \\
\hline FS814 & TGAAGGCAAAGGTTGAAAGC & TGCTGGTAGGAGTTGGGACA & 342 \\
\hline FS834 & CTCGGTTGGCATTGGTCATA & CATTTACACCTGCTTCTTTA & 351 \\
\hline FS681 & CGAGCCTGAAAGTGTTAGAT & TGATGAAAGTCCAGCAAGAT & 163 \\
\hline FS899 & GGGACTTTCTATCGGCTTAC & CTCACTTCCACTGCCACCAC & 181 \\
\hline FS928 & CCGCAGAAGAAGAAATGAAA & CGAGCAGCGATACTATGTCC & 117 \\
\hline Actin & CAGTGTTTGGATTGGAGGTT & TCTCGGGTTCCATTTCCATC & 139 \\
\hline
\end{tabular}




\section{RESULTS}

\section{Construction of the subtracted cDNA library}

To identify the warm day- and cool night-induced flowering genes, an SSH library, which was enriched for cDNAs corresponding to warm day- and cool night-induced flowering genes, was constructed. The cDNA fragments obtained were subcloned into a pGEM-T easy vector. A total of 650 white colonies were randomly isolated from LB-ampicillin medium. Each colony was used to amplify the inserted sequences. Most of the inserts ranged from 200 to $1200 \mathrm{bp}$. After editing, 450 non-redundant ESTs exhibited significant homology to plant genes. On the basis of their putative functions, the ESTs were annotated and classified into eleven categories as follows: metabolism, development, cell defense and stress, transcription regulation, signal transduction, transportation, protein synthesis and modification, photosynthesis, cell structure and component, energy, unknown and no hit proteins (Table 2). The metabolism category (consisting of six sub-classes: amino acid, C-compound, nucleotide, lipid and fatty acid, phosphate, and secondary metabolism) contained 98 distinct deduced proteins from 107 ESTs, which accounted for 23.78\% (107/450) of the classified ESTs. The category protein synthesis and modification contained 53 distinct proteins deduced from $53 \mathrm{ESTs}$, which accounted for $11.78 \%$ of the classified ESTs. Other categories were as follows: development (15 distinct proteins; 15 ESTs; 3.33\%), cell defense and stress (23 distinct proteins; 24 ESTs; $5.33 \%$ ), transcription regulation (24 distinct proteins; 24 ESTs; $5.33 \%$ ), signal transduction (48 distinct proteins; 48 ESTs; 10.67\%), transportation (17 distinct proteins; $18 \mathrm{ESTs} ; 4.00 \%$ ), photosynthesis ( 9 distinct proteins; 9 ESTs; $2.00 \%$ ), cell structure and component (31 distinct proteins; 33 ESTs; $7.33 \%$ ), energy (16 distinct proteins; 19 ESTs; $4.22 \%$ ), unknown and no hit protein (100 ESTs; $22.22 \%$ ). Putative functions of all ESTs were annotated according to the highest scoring matches by BLAST in NCBI. Four hundred and fifty ESTs were deposited in NCBI dbEST database of GenBank with accession numbers of JK720314-JK720763. Some of the ESTs deposited in GenBank under the accession numbers are shown in Table 3.

Table 2. Functional categories of flowering-related ESTs induced by warm day and cool night conditions in Phalaenopsis hybrid Fortune Saltzman.

\begin{tabular}{lcr}
\hline Functional classification & Number of ESTs & Ratio (\%) \\
\hline Metabolism & 107 & 23.78 \\
Amino acid metabolism & 19 & 4.22 \\
C-compound metabolism & 18 & 4.00 \\
Nucleotide metabolism & 26 & 5.78 \\
Lipid and fatty acid metabolism & 9 & 2.00 \\
Phosphate metabolism & 4 & 0.89 \\
Secondary metabolism & 31 & 6.89 \\
Development & 15 & 3.33 \\
Cell defence and stress & 24 & 5.33 \\
Transcription regulation & 24 & 5.33 \\
Signal transduction & 48 & 10.67 \\
Transportation & 18 & 4.00 \\
Protein synthesis and modification & 53 & 11.78 \\
Photosynthesis & 9 & 2.00 \\
Cell structure and component & 33 & 7.33 \\
Energy & 19 & 4.22 \\
Unknown and no hit protein & 100 & 22.22 \\
Total & 450 & 100.00 \\
\hline
\end{tabular}


Table 3. Genes differentially expressed in Phalaenopsis hybrid Fortune Saltzman spikes induced by warm day and cool night condition.

\begin{tabular}{|c|c|c|c|c|}
\hline Clone No. & $\begin{array}{l}\text { GenBank } \\
\text { accession No. }\end{array}$ & $\begin{array}{l}\text { Length } \\
\text { (bp) }\end{array}$ & BLAST annotation (GenBank accession No.) & E value \\
\hline \multicolumn{5}{|c|}{ Amino acid metabolism } \\
\hline FS94 & JK720363 & 149 & Cysteine synthase [Citrullus lanatus subsp vulgaris] (BAA05965.1) & $8 \mathrm{e}-21$ \\
\hline FS344* & JK720495 & 520 & S-adenosylmethionine synthetase [Gossypium hirsutum] (ADN96174.1) & $2 e-71$ \\
\hline \multicolumn{5}{|c|}{ C-compound metabolism } \\
\hline FS82* & JK720358 & 781 & NAD-dependent malate dehydrogenase [Prunus armeniaca] (ADN87327.1) & $1 e-87$ \\
\hline \multicolumn{5}{|c|}{ Nucleotide metabolism } \\
\hline FS276* & JK720451 & 674 & Caffeoyl-CoA 3-O methyltransferase [Coffea canephora] (ABO77959.1) & $3 e-86$ \\
\hline FS465 & JK720546 & 563 & ATP-dependent RNA helicase, putative [Ricinus communis] (XP_002515245.1) & $3 e-51$ \\
\hline \multicolumn{5}{|c|}{ Fatty acid and lipid metabolism } \\
\hline FS944 & JK720752 & 274 & $\begin{array}{l}\text { Long-chain-fatty-acid-CoA ligase family protein [Arabidopsis lyrata subsp lyrata] } \\
\text { (XP_002880290.1) }\end{array}$ & $2 \mathrm{e}-27$ \\
\hline \multicolumn{5}{|c|}{ Phosphate metabolism } \\
\hline FS588 & JK720595 & 818 & Putative purple acid phosphatase [Arabidopsis thaliana] (AAW29952.1) & $1 e-63$ \\
\hline \multicolumn{5}{|c|}{ Secondary metabolism } \\
\hline FS278* & JK720453 & 512 & Dihydroflavonol 4-reductase [Bromheadia finlaysoniana] (AAB62873.1) & $4 e-80$ \\
\hline FS327* & JK720481 & 1127 & Naringenin 3-dioxygenase [Bromheadia finlaysoniana] (CAA61486.1) & 0.0 \\
\hline FS383* & JK720510 & 393 & Cytochrome P450 [Zea mays] (ACG38359.1) & $1 e-38$ \\
\hline FS397* & JK720515 & 666 & Sesquiterpene synthase [Vanda hybrid cultivar] (ABX57720.1) & $4 \mathrm{e}-47$ \\
\hline \multicolumn{5}{|c|}{ Signal transduction } \\
\hline FS33* & JK720330 & 609 & Early flowering protein 1 [Elaeis guineensis] (ACF06553.1) & $3 e-37$ \\
\hline FS68 & JK720352 & 529 & $\begin{array}{l}\text { Serine-threonine protein kinase, plant-type, putative [Ricinus communis] } \\
\text { (XP_002530200.1) }\end{array}$ & $2 \mathrm{e}-40$ \\
\hline FS612 & JK720609 & 704 & Serine/threonine-protein kinase Nek4 [Zea mays] (NP_001152012.1) & $6 e-96$ \\
\hline FS834* & JK720703 & 395 & Adenosine kinase 2 [Oryza sativa Indica Group] (ABR̄25519.1) & $2 e-53$ \\
\hline \multicolumn{5}{|c|}{ Transportation } \\
\hline FS46 & JK720339 & 385 & PIP1_5/PIP1D [Arabidopsis lyrata subsp lyrata] (XP_002869782.1) & $2 \mathrm{e}-45$ \\
\hline FS311 & JK720470 & 499 & Potassium efflux antiporter [Populus trichocarpa] (X) $\left.\overline{\mathrm{P}} \_002308566.1\right)$ & $2 \mathrm{e}-13$ \\
\hline \multicolumn{5}{|c|}{ 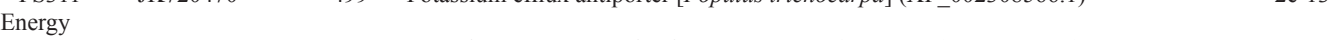 } \\
\hline FS716 & JK720661 & 196 & Vacuolar $\mathrm{H}^{+}$-ATPase subunit C [Gossypium hirsutum] (ABH07428.1) & $2 \mathrm{e}-23$ \\
\hline FS752 & JK720675 & 701 & $\begin{array}{l}\text { Putative DNA-dependent ATPase SNF2H [Oryza sativa Japonica Group] } \\
\text { (BAD61441.1) }\end{array}$ & $2 \mathrm{e}-51$ \\
\hline \multicolumn{5}{|c|}{ (2) } \\
\hline FS184* & JK720404 & 451 & KNOX1 [Agave tequilana] (ADN43388.1) & $2 \mathrm{e}-27$ \\
\hline FS527* & JK720571 & 809 & Flowering locus T [Cymbidium goeringii] (ADI58462.1) & $3 e-90$ \\
\hline FS652* & JK720623 & 583 & $\begin{array}{l}\text { AP2 domain-containing transcription factor [Populus trichocarpa] } \\
\text { (XP_002302387.1) }\end{array}$ & $2 \mathrm{e}-42$ \\
\hline FS715* & JK720660 & 879 & $\begin{array}{l}\text { Flowering time control protein isoform OsFCA-2 [Oryza sativa Indica Group] } \\
\text { (AAQ74972.1) }\end{array}$ & $4 e-31$ \\
\hline \multirow{2}{*}{$\begin{array}{ll}\text { FSP14* } \\
\text { FS928* }\end{array}$} & JK720695 & 603 & AP1-related protein [Phalaenopsis amabilis] (AAZ76263.1) & $3 e-82$ \\
\hline & JK720743 & 329 & Knotted1-like homeobox protein [Dendrobium grex Madame Thong-In] (CAB88029.1) & $6 e-34$ \\
\hline \multicolumn{5}{|c|}{ Transcription regulation } \\
\hline FS71* & JK720353 & 466 & Retrotransposon protein Ty3-gypsy subclass [Zea mays] (ACG35788.1) & $1 e-29$ \\
\hline FS89* & JK720361 & 677 & $\begin{array}{l}\text { Helix-loop-helix DNA-binding domain protein [Oryza sativa Japonica Group] } \\
\text { (NP 001051465.1) }\end{array}$ & $3 e-19$ \\
\hline FS210* & JK720416 & 834 & $\begin{array}{l}\text { Zinc finger }\left(\mathrm{C}_{3} \mathrm{HC}_{4} \text {-type } \mathrm{RING} \text { finger) family protein [Arabidopsis thaliana] }\right. \\
\text { (NP_564263.1) }\end{array}$ & $1 e-25$ \\
\hline \multirow{2}{*}{$\begin{array}{l}\text { FS413 } \\
\text { FS449* }\end{array}$} & JK720519 & 521 & MYB̄134 [Glycine max] (ABH02878.1) & $5 e-07$ \\
\hline & JK720535 & 629 & ppha curcas] (ADF59041.1) & $1 e-50$ \\
\hline FS681* & JK720638 & 597 & Transposon protein [Zea mays] (NP_001148044.1) & $5 e-88$ \\
\hline FS789* & JK720689 & 672 & MYB transcription factor R2R3-like protein [Populus tremuloides] (ACR83705.1) & $4 e-52$ \\
\hline FS899* & JK720729 & 831 & ARF domain class transcription factor [Malus $\mathrm{x}$ domestica] (ADL36581.1) & $1 e-46$ \\
\hline \multicolumn{5}{|c|}{ Protein synthesis and modification } \\
\hline FS376 & JK720507 & 318 & Asparaginyl endopeptidase [Vigna radiata] (AAK15049.1) & $8 \mathrm{e}-39$ \\
\hline FS469* & JK720548 & 242 & Leucine-rich repeat-containing protein 40 [Zea mays] (ACG39716.1) & $4 \mathrm{e}-09$ \\
\hline \multicolumn{5}{|c|}{ Photosynthesis } \\
\hline FS225 & JK720425 & 338 & Photosystem 1 subunit A [Schisandra sp SM-2010] (ADN44177.1) & $2 e-54$ \\
\hline
\end{tabular}

Continued on next page 


\begin{tabular}{|c|c|c|c|c|}
\hline Clone No. & $\begin{array}{c}\text { GenBank } \\
\text { accession No. }\end{array}$ & $\begin{array}{l}\text { Length } \\
\text { (bp) }\end{array}$ & Blast annotation (GenBank accession No.) & E value \\
\hline \multicolumn{5}{|c|}{ Cell defence and stress } \\
\hline FS14 & JK720322 & 587 & Mannose-specific lectin [Dioscorea polystachya] (BAD67184.1) & $8 \mathrm{e}-19$ \\
\hline FS40 & JK720335 & 591 & Class III peroxidase [Oncidium Gower Ramsey] (ABC02343.1) & $3 e-45$ \\
\hline \multicolumn{5}{|c|}{ Cell component and structure } \\
\hline FS49 & JK720341 & 402 & Cellulose synthase-like protein C10 [Oryza sativa Indica Group] (Q84Z01.1) & $9 e-65$ \\
\hline \multicolumn{5}{|c|}{ Unkown and no hits protein } \\
\hline FS32 & JK720329 & 584 & No hits & \\
\hline FS379 & JK720509 & 414 & Unknown [Zea mays] (ACR36679.1) & $2 \mathrm{e}-17$ \\
\hline FS494* & JK720562 & 899 & Unnamed protein product [Vitis vinifera] (CBI22809.3) & $2 e-67$ \\
\hline
\end{tabular}

*Clones selected for further real-time PCR analysis.

\section{Gene expression by real-time PCR}

To further confirm the expression profile of the genes obtained from SSH library, 24 genes belonging to various functional categories related to flowering transition, were examined in juvenile apical leaves and spikes induced by warm day and cool night conditions at different developmental stages using real-time PCR. The primer pairs of 24 genes are shown in Table 1. Compared with the levels in apical leaves, 21 genes showed upregulated levels in spikes at certain developmental stages, while expressions of 3 other genes slightly or remarkably decreased in spikes examined (Figure 1). These results indicated that the real-time PCR data agreed with the SSH data at $87.5 \%$. Considering the inevitable technical errors introduced either from SSH construction or real-time PCR, it was concluded that overall there was a good agreement between the SSH data and real-time PCR results.

Real-time PCR also showed that 5 flowering-related ESTs (FS184, KNOX1; FS527, FT; FS814, AP1; FS652, AP2; FS928, knotted1-like homeobox protein) were significantly upregulated in induced spikes at 0-3 $\mathrm{mm}$ sizes (Figure 1). After spike development, expression profiles of these 5 genes showed diverse trends (Figure 1). The transcript levels of both $F T$ and $A P 1$ were gradually reduced in tested spikes, and the transcripts of $K N O X 1$ were first consistent in spikes at $0-15-\mathrm{mm}$ sizes, and then gradually decreased in spikes at $15-35-\mathrm{mm}$ sizes, but the transcripts of these 3 genes were still higher in the spikes tested than in apical leaves. The expression patterns of AP2 and knotted1-like homeobox protein showed fluctuating changes in the spikes tested. The transcripts of $A P 2$ were gradually decreased in $20-35-\mathrm{mm}$ spikes and lower than in apical leaves, while the transcripts of knottedl-like homeobox protein were higher in spikes tested than in apical leaves. Interestingly, the transcript levels of one EST related to flowering time control protein FCA (FS715) in apical leaves were higher than in all the spikes tested, except in 15-20-mm spikes (Figure 1).

Other warm day- and cool night-induced genes confirmed by real-time PCR were involved in signal transduction (FS33, early flowering protein 1; FS834, adenosine kinase 2), metabolism (FS82, NAD-dependent malate dehydrogenase; FS276, caffeoyl-CoA 3-O methyltransferase; FS278, dihydroflavonol 4-reductase; FS327, naringenin 3-dioxygenase; FS344, S-adenosylmethionine synthetase; FS383, cytochrome P450; FS397, sesquiterpene synthase), transcription regulation (FS89, Helix-loop-helix DNA-binding domain containing protein; FS449, NAC; FS681, transposon protein; FS789, R2R3-like MYB; and FS899, ARF domain class transcription factor) and protein synthesis and modification (FS469, leucine-rich repeat-containing protein 40). 

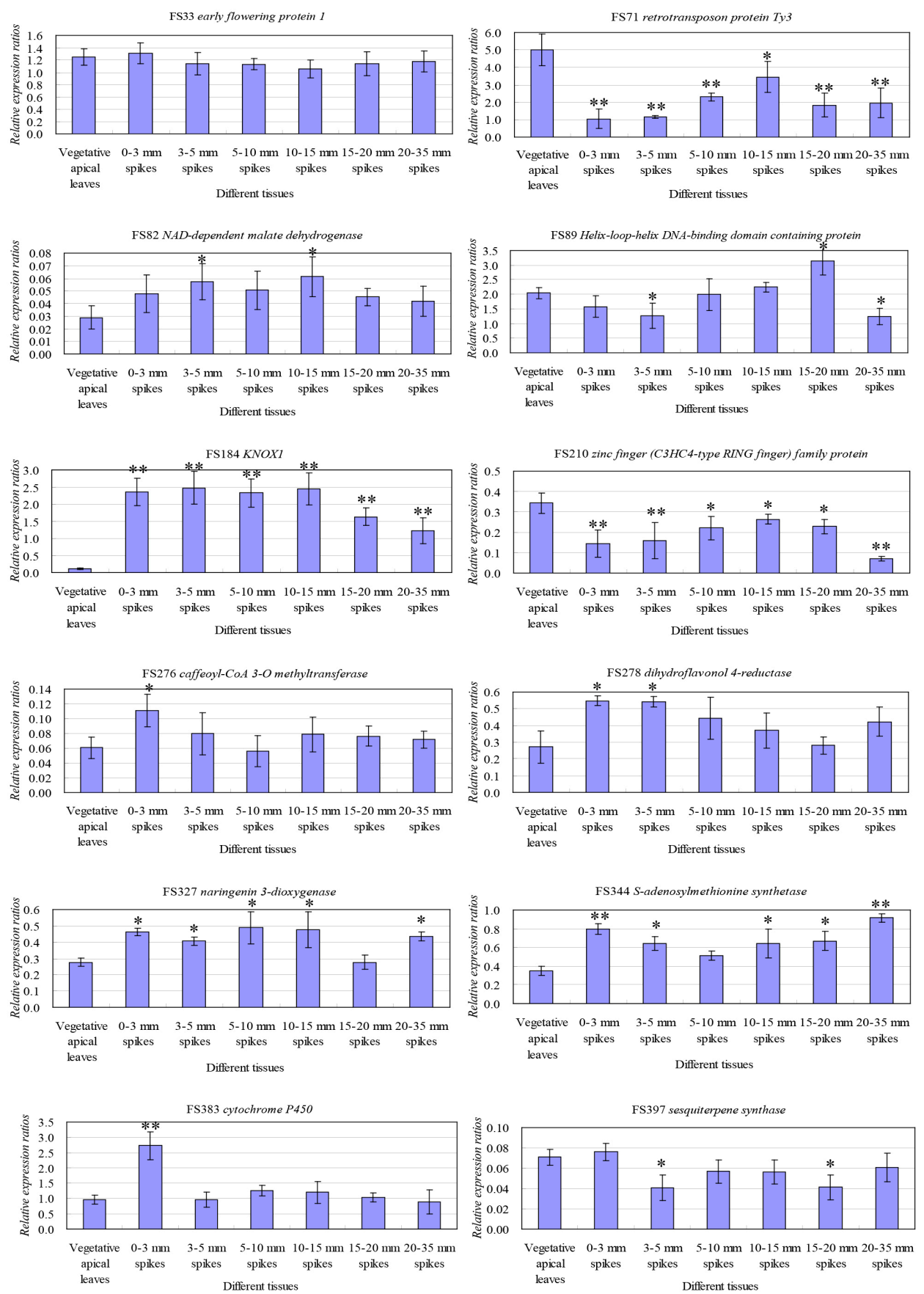

Figure 1. Results of real-time PCR for 24 genes obtained by suppression subtractive hybridization. All expression values were normalized to the values of the actin gene. Significance was indicated as $* \mathrm{P}<0.05 ; * * \mathrm{P}<0.01$.

Continued on next page 
Figure 1. Continued.
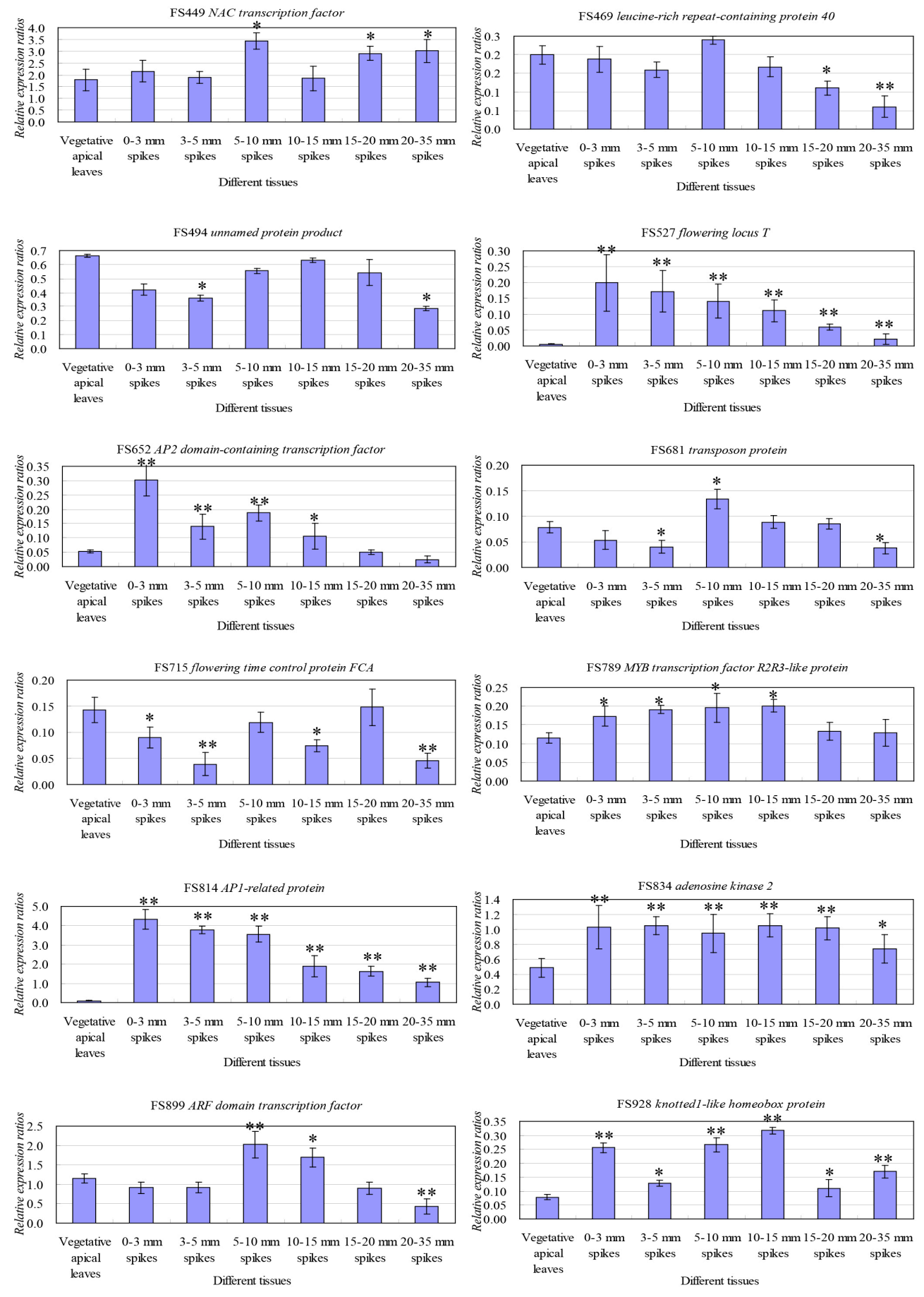

Genetics and Molecular Research 13 (3): 7037-7051 (2014) 
In contrast, the genes downregulated in all spikes tested induced by warm day and cool night conditions were mainly involved in transcription regulation (FS71, retrotransposon protein Ty3; FS210, C3HC4-type RING finger) and unknown (FS494, unnamed protein) (Figure 1).

\section{DISCUSSION}

In this study, we constructed one forward subtracted cDNA library enriched for genes in spikes of Phalaenopsis hybrid Fortune Saltzman induced by warm days and cool nights. Our primary data provided new insights to the molecular events of flowering initiation in Phalaenopsis orchids that were induced by warm day and cool night conditions. The molecular mechanisms of flowering initiation in Phalaenopsis orchids are currently unclear. For clarifying the molecular mechanisms of flowering initiation in Phalaenopsis orchids, it is important to find out the flowering-related genes during floral transition. The SSH technique applied in this study was effective. There were 450 identified and sequenced ESTs. Their expressions were induced, increased or declined in Phalaenopsis hybrid Fortune Saltzman spikes at different developmental stages under warm days and cool nights, compared with the levels in juvenile apical leaves under warm daily temperatures. The diverse function of regulated genes found in our study revealed the complexity and variety of pathways involved in warm day and cool night treatment response in Phalaenopsis hybrid Fortune Saltzman, as shown for other plants.

In the present study, a number of Phalaenopsis hybrid Fortune Saltzman ESTs are homologous to flowering-related genes in various plants, such as Chinese Cymbidium (Huang et al., 2012; Xiang et al., 2012), Doritaenopsis hybrid (Sun et al., 2012), etc. Other ESTs identified in this study show sequence similarities with genes encoding proteins related to signal transduction, transportation, transcription regulation, and metabolic processes. Furthermore, real-time PCR was used to study the expressions of 24 genes selected (with putative functions) derived from the sequenced ESTs (Figure 1). Among them, 21 genes were found to be up-regulated in warm day- and cool night-induced spikes at some stages, compared with the levels in apical leaves under warm daily temperatures, while expressions of 3 other genes slightly or remarkably decreased in induced spikes at all developmental stages. Thus, selected warm day and cool night conditions induced Phalaenopsis hybrid Fortune Saltzman genes possibly contributing to the floral transition that will be discussed in the following sections.

\section{Flowering pathway-related genes}

Flowering pathway-related genes were identified from our library by BLASTx searches as described above and 9 putative flowering genes were identified. They were $L H Y$ (late elongated hypocotyl) (FS750), DNA J homolog (FS348), FCA (FS715), FVE (FS445), FT (FS527), AP1 (FS814), AP2 (FS652), KNOX1 (FS184), and knotted-like homeobox protein (FS928). Of these genes, the 3 genes ( $L H Y, D N A$ J homolog, FVE) transcript levels in induced spikes and juvenile apical leaves were not confirmed by real-time PCR, as we could not design appropriate primers. In A. thaliana, $J 3$ was involved in flowering signals from several genetic pathways and promoted flowering through directly activating the transcription of SOC1 and FT during the floral transition (Shen et al., 2011); LHY participated in the photoperiodic control of flowering (Schaffer et al., 1998); FVE was involved in autonomous and cold response pathways regulating flowering time (Ausín et al., 2004; Jeon and Kim, 2011); FCA controlled 
flowering by fluctuating ambient conditions and negative autoregulation pathways (Macknight et al., 1997; Quesada et al., 2003; Jung et al., 2012). In Doritaenopsis hybrid, DhFVE was also involved in the regulation of flowering (Sun et al., 2012). In our study, FT, AP1, AP2, KNOX1, and knotted-like homeobox protein transcripts accumulated to higher levels and $F C A$ transcripts accumulated to lower levels in spikes of different sizes $(0-15 \mathrm{~mm})$ relative to juvenile apical leaves (Figure 1). In addition, expression patterns of $F T$ and $A P 1$ were positively correlated with each other by real-time PCR in different developmental spikes (Figure 1). On the basis of the above findings, it is tempting to speculate that spikes of Phalaenopsis hybrid Fortune Saltzman induced by warm days and cool nights were at least related to 4 flowering genetic pathways: fluctuating ambient temperature, cold response, photoperiodic, and autonomous pathways. Future study is required to elucidate the function of these genes in Phalaenopsis hybrid Fortune Saltzman in the molecular flowering network.

\section{Genes involved in metabolism}

During floral transition induced by warm day and cool night conditions, expression of various Phalaenopsis hybrid Fortune Saltzman genes were involved in metabolism and biosynthesis of carbohydrates, amino acids, fatty acids, and secondary substances. S-adenosylmethionine synthase (SAMS) plays a regulatory role in the synthesis of methionine and other aspartate-derived amino acids (Tabor and Tabor, 1984). In the present study, the remarkably upregulated transcripts of $S A M S$ in $0-5-$ and $10-25-\mathrm{mm}$ spikes were relative to juvenile apical leaves (Figure 1). The results suggested that early differentiation and later developmental stages of spikes enhanced activity of amino acid metabolism, giving rise to more methionine and other aspartate-derived amino acids. In addition, we also found slightly or significantly increased levels of transcripts encoding NAD-dependent malate dehydrogenase (FS82), caffeoyl-CoA 3-O methyltransferase (FS276), dihydroflavonol 4-reductase (FS278), naringenin 3-dioxygenase (FS327), cytochrome P450 (FS383), and sesquiterpene synthase (FS397) in spikes of some stages relative to juvenile apical leaves. Expression regulation mechanisms of these genes in floral transition will be investigated in future studies.

\section{Genes involved in transcriptional regulation}

Transcription factors mediate regulation and expression of genes during diverse processes of plant life cycle. In warm day- and cool night-induced spikes, specific transcription factors encoding NAC, MYB and ARF proteins were obtained. These proteins also participated in flower organ development (Sablowski and Meyerowitz, 1998), amino acid metabolism (ElKereamy et al., 2012), flavonoid biosynthesis (Nakatsuka et al., 2012), and red fruit-flesh phenotypes (Chagné et al., 2013), as well as response to different biotic and abiotic stresses (El-Kereamy et al., 2012; Li et al., 2012b). Compared with the expression levels in juvenile apical leaves, the accumulated transcripts of $N A C$ (FS449) and R2R3-like MYB (FS789) were higher in all spikes tested, while the accumulated transcripts of $A R F$ (FS899) were lower in early and later stages of spikes (Figure 1). These results indicated that $N A C$ and $R 2 R 3$-like $M Y B$ may positively regulate spike differentiation and development, and $A R F$ may negatively regulate spike early differentiation and later developmental stages.

In this study, some regulators were also obtained, such as retrotransposon protein, 
transposon protein and zinc finger protein. The accumulated transcripts of genes encoding retrotransposon protein Ty3 (FS71) and $\mathrm{C}_{3} \mathrm{HC}_{4}$ type ring finger (FS210) in different sizes of spikes were lower than in juvenile apical leaves. In addition, the gene (FS681) encoding transposon protein accumulated lower levels in spikes' early differentiation and later developmental stages than in juvenile apical leaves (Figure 1). These findings indicated that the 3 genes may negatively regulate spike early differentiation and later developmental stages. Future study is required to elucidate the functions of these genes in spike differentiation and development in Phalaenopsis hybrid Fortune Saltzman.

\section{Genes involved in signal transduction}

Genes of Phalaenopsis hybrid Fortune Saltzman involved in signal transduction during spike differentiation and development were also identified in this study. Examples of this category are genes encoding a protein kinase, a serine-threonine protein kinase, a glycogen synthase kinase, a signal recognition particle protein, an adenosine kinase and an SKP1/ ASK1-like protein. The function of these genes in Phalaenopsis hybrid Fortune Saltzman remains to be elucidated. In the current study, the accumulated higher transcripts of adenosine kinase 2 in spikes relative to juvenile apical leaves indicated the involvement of signaling events in response to warm day and cool night conditions. In fact, the $S K P 1$ homolog $A S K 1$ regulated development and interacted with the $U F O$ gene to control floral organ identity in $A$. thaliana (Zhao et al., 1999). Moreover, SKPl was also involved in abscisic acid signaling to regulate seed germination, stomatal opening and root growth in $A$. thaliana (Li et al., 2012a).

\section{Other genes}

In the processes of spike differentiation and development induced by warm day and cool night conditions, expression of many genes known to be involved in defense- and stress-associated reactions, transportation, energy, and cell wall seems to be induced. Genes belonging to these categories include genes encoding heat shock protein, peroxidase, cold-acclimation specific protein, lectin, potassium channel, sugar transporter, ATPase, hydrolase, oxidoreductase, and cellulose. The function of these genes in Phalaenopsis hybrid Fortune Saltzman remains to be validated.

Finally, our study found that an unexpected high number of Phalaenopsis hybrid Fortune Saltzman ESTs corresponded to novel genes or putative proteins that had no determined function. It is interesting and of great importance to examine the transcript levels of these genes to gain insights into the molecular functions of these genes in spike differentiation and development induction by warm day and cool night conditions.

In summary, the present study indicated that the SSH technique could provide valuable insights into the expression patterns of genes associated with spike differentiation and development induction by warm day and cool night conditions in Phalaenopsis orchids. Sequence analysis of the library resulted in 450 Phalaenopsis hybrid Fortune Saltzman ESTs. On the basis of real-time PCR analysis of the selected genes, the validity of the library with respect to warm day- and cool night-induced expression was confirmed. Corresponding genes were predicted to encode proteins with various functions, suggesting the complex molecular alterations occurring in spike differentiation and development induction by warm days and cool nights in Phalaenopsis plants. Some of the identified ESTs were homologous to plant 
flowering genes related to several flowering genetic pathways. Moreover, $22.22 \%$ of the warm day- and cool night-induced ESTs in spikes matched genes with unknown function in the NCBI database. Furthermore, we have cloned the full-length cDNAs of several genes (e.g., $F T, N A C$, and R2R3-like MYB) that could play important roles in spike differentiation and development induced by warm days and cool nights. The characterization of their functions is being undertaken to determine whether these warm day- and cool night-responsive genes have a role in flowering-time control. Such research effort will provide further insights into molecular mechanisms of floral transition induction by warm days and cool nights in Phalaenopsis orchids.

\section{ACKNOWLEDGMENTS}

Research supported by the Guangdong Academy of Agricultural Sciences Fund (\#201019) and the Guangzhou Municipal Science and Technology Project (\#12C14071654).

\section{REFERENCES}

Abe M, Kobayashi Y, Yamamoto S, Daimon Y, et al. (2005). FD, a bZIP protein mediating signals from the floral pathway integrator $F T$ at the shoot apex. Science 309: 1052-1056.

Altschul SF, Madden TL, Schaffer AA, Zhang J, et al. (1997). Gapped BLAST and PSI-BLAST: a new generation of protein database search programs. Nucleic Acids Res. 25: 3389-3402.

An FM, Hsiao SR and Chan MT (2011). Sequencing-based approaches reveal low ambient temperature-responsive and tissue-specific microRNAs in Phalaenopsis orchid. PLoS One 6: e18937.

Ausín I, Alonso-Blanco C, Jarillo JA, Ruiz-Garcia L, et al. (2004). Regulation of flowering time by FVE, a retinoblastomaassociated protein. Nat. Genet. 36: 162-166.

Chagné D, Lin-Wang K, Espley RV, Volz RK, et al. (2013). An ancient duplication of apple MYB transcription factors is responsible for novel red fruit-flesh phenotypes. Plant Physiol. 161: 225-239.

Chen D, Guo B, Hexige S, Zhang T, et al. (2007). SQUA-like genes in the orchid Phalaenopsis are expressed in both vegetative and reproductive tissues. Planta 226: 369-380.

Chen WH, Tseng YC, Liu YC, Chuo CM, et al. (2008). Cool-night temperature induces spike emergence and affects photosynthetic efficiency and metabolizable carbohydrate and organic acid pools in Phalaenopsis aphrodite. Plant Cell Rep. 27: 1667-1675.

Chen WS, Liu HY, Liu ZH and Yang L (1994). Gibberellin and temperature influence carbohydrate content and flowering in Phalaenopsis. Physiol. Plantarum 90: 391-395.

Chen YH, Tsai YJ, Huang JZ and Chen FC (2005). Transcription analysis of peloric mutants of Phalaenopsis orchids derived from tissue culture. Cell Res. 15: 639-657.

Corbesier L, Vincent C, Jang S, Fornara F, et al. (2007). FT protein movement contributes to long-distance signaling in floral induction of Arabidopsis. Science 316: 1030-1033.

El-Kereamy A, Bi YM, Ranathunge K, Beatty PH, et al. (2012). The rice R2R3-MYB transcription factor OsMYB55 is involved in the tolerance to high temperature and modulates amino acid metabolism. PLoS One 7: e52030.

Endo M and Ikusima I (1989). Diurnal rhythm and characteristics of photosynthesis and respiration in the leaf and root of a Phalaenopsis plant. Plant Cell Physiol. 30: 43-47.

Guo WJ and Lee N (2006). Effect of leaf and plant age, and day/night temperature on net $\mathrm{CO}_{2}$ uptake in Phalaenopsis amabilis var. Formosa. J. Am. Soc. Hort. Sci. 131: 320-326.

Hew CS and Yong JWH (1997). Physiology of Tropical Orchids in Relation to the Industry. World Scientific, Singapore. Hsiao YY, Tsai WC, Kuoh CS, Huang TH, et al. (2006). Comparison of transcripts in Phalaenopsis bellina and Phalaenopsis equestris (Orchidaceae) flowers to deduce monoterpene biosynthesis pathway. BMC Plant Biol. 6: 14.

Hsiao YY, Chen YW, Huang SC, Pan ZJ, et al. (2011). Gene discovery using next-generation pyrosequencing to develop ESTs for Phalaenopsis orchids. BMC Genomics 12: 360.

Huang W, Fang Z, Zeng S, Zhang J, et al. (2012). Molecular Cloning and Functional Analysis of Three FLOWERING LOCUS T (FT) Homologous Genes from Chinese Cymbidium. Int. J. Mol. Sci. 13: 11385-11398. 
Jeon J and Kim J (2011). FVE, an Arabidopsis homologue of the retinoblastoma-associated protein that regulates flowering time and cold response, binds to chromatin as a large multiprotein complex. Mol. Cells 32: 227-234.

Jung JH, Seo PJ, Ahn JH and Park CM (2012). Arabidopsis RNA-binding protein FCA regulates microRNA172 processing in thermosensory flowering. J. Biol. Chem. 287: 16007-16016.

Lee J and Lee I (2010). Regulation and function of SOC1, a flowering pathway integrator. J. Exp. Bot. 61: 2247-2254.

Lee J, Oh M, Park H and Lee I (2008). SOC1 translocated to the nucleus by interaction with AGL24 directly regulates LEAFY. Plant J. 55: 832-843.

Li C, Liu Z, Zhang Q, Wang R, et al. (2012a). SKP1 is involved in abscisic acid signalling to regulate seed germination, stomatal opening and root growth in Arabidopsis thaliana. Plant Cell Environ. 35: 952-965.

Li DM, Wang JH, Peng SL, Zhu GF, et al. (2012b). Molecular cloning and characterization of two novel NAC genes from Mikania micrantha (Asteraceae). Genet. Mol. Res. 11: 4383-4401.

Macknight R, Bancroft I, Page T, Lister C, et al. (1997). FCA, a gene controlling flowering time in Arabidopsis, encodes a protein containing RNA-binding domains. Cell 89: 737-745.

Nakatsuka T, Saito M, Yamada E, Fujita K, et al. (2012). Isolation and characterization of GtMYBP3 and GtMYBP4, orthologues of R2R3-MYB transcription factors that regulate early flavonoid biosynthesis, in gentian flowers. $J$. Exp. Bot. 63: 6505-6517.

Pollet B, Kromwijk A, Vanhaecke L, Dambre P, et al. (2011a). A new method to determine the energy saving night temperature for vegetative growth of Phalaenopsis. Ann. Appl. Biol. 158: 331-345.

Pollet B, Vanhaecke L, Dambre P, Lootens P, et al. (2011b). Low night temperature acclimation of Phalaenopsis. Plant Cell Rep. 30: 1125-1134.

Quesada V, Macknight R, Dean C and Simpson GG (2003). Autoregulation of FCA pre-mRNA processing controls Arabidopsis flowering time. EMBO J. 22: 3142-3152.

Sablowski RW and Meyerowitz EM (1998). A homolog of NO APICAL MERISTEM is an immediate target of the floral homeotic genes APETALA3/PISTILLATA. Cell 92: 93-103.

Sakanishi Y, Imanishi H and Ishida G (1980). Effect of temperature on growth and flowering of Phalaenopsis amabilis. Bull. Univ. Osaka Pref. Ser. B 32: 1-9.

Schaffer R, Ramsay N, Samach A, Corden S, et al. (1998). The late elongated hypocotyl mutation of Arabidopsis disrupts circadian rhythms and the photoperiodic control of flowering. Cell 93: 1219-1229.

Shen L, Kang YG, Liu L and Yu H (2011). The J-domain protein J3 mediates the integration of flowering signals in Arabidopsis. Plant Cell 23: 499-514.

Srikanth A and Schmid M (2011). Regulation of flowering time: all roads lead to Rome. Cell Mol. Life Sci. 68: 2013-2037.

Sun X, Qin Q, Zhang J, Zhang C, et al. (2012). Isolation and characterization of the FVE gene of a Doritaenopsis hybrid involved in the regulation of flowering. Plant Growth Regul. 68: 77-86.

Tabor CW and Tabor H (1984). Methionine adenosyltransferase (S-adenosylmethionine synthetase) and S-adenosylmethionine decarboxylase. Adv. Enzymol. Relat. Areas Mol. Biol. 56: 251-282.

Tsai WC, Hsiao YY, Lee SH, Tung CW, et al. (2006). Expression analysis of the ESTs derived from the flower buds of Phalaenopsis equestris. Plant Sci. 170: 426-432.

Wang YT (1995). Phalaenopsis orchid light requirement during the induction of spiking. Hort. Sci. 30: 59-61.

Xiang L, Li X, Qin D, Guo F, et al. (2012). Functional analysis of FLOWERING LOCUS T orthologs from spring orchid (Cymbidium goeringii Rchb. f.) that regulates the vegetative to reproductive transition. Plant Physiol. Biochem. 58: 98-105.

Zhang JX, Wu KL, Tian LN, Zeng SJ, et al. (2011). Coning and characterization of a novel CONSTANS-like gene from Phalaenopsis hybrida. Acta Physiol. Plant. 33: 409-417.

Zhao D, Yang M, Solava J and Ma H (1999). The ASK1 gene regulates development and interacts with the UFO gene to control floral organ identity in Arabidopsis. Dev. Genet. 25: 209-223. 